\title{
O panóptico verde: Notas sobre os regimes de ambientalidade
}

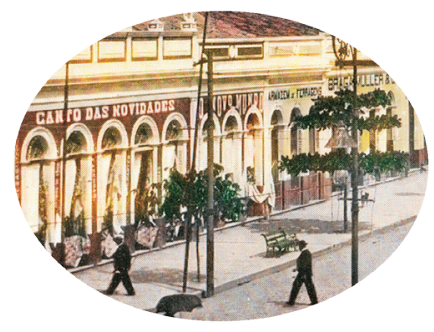

Luiz Fernando de Souza Santos*

\section{Resumo}

Os debates sobre a crise ambiental nas sociedades contemporâneas têm acentuado as soluções técnicas. E o desenvolvimento sustentável é o principal termo nos argumentos econômicos, políticos e científicos no que tange à promoção de tais soluções. Este é um processo, por sua vez, no qual o ambiente emerge como tática de poder que regula a controla o uso do espaço e a exploração dos recursos naturais pelo homem, gerando subjetividades ambientalizadas. O presente trabalho propõe uma análise crítica desses discursos e práticas ambientalistas. Os argumentos de Michel Foucault e as reflexões foucaultianas desenvolvidas por Timothy W. Luke constitui-se em base teórica e metodológica para uma interpretação crítica do processo de ambientalização.

Palavras-chaves: Biopoder; governamentalidade; ambientalidade.

\begin{abstract}
Debates over environmental crises in contemporary societies have focused on technical solutions. And sustainable development is the principal term in economics, political and scientific arguments for promotion theses solutions. This is a process, at the same time, in which the environment emerges as tactics of power that regulates and controls the use of the space and exploitation of

\footnotetext{
* Mestre em Sociedade e Cultura na Amazônia, professor do Instituto de Ciências Exatas e Tecnologia, da Universidade Federal do Amazonas. E-mail: luizfernando@ufam.edu.br
} 
the natural resources by the man, generating environmentalizeds subjectivities. This work proposes a critical analyze theses environmentalists discourses and practices. The Michel Foucault's arguments and the foucaultians reflections developed for Timothy W. Luke is the theoretical and methodological base for the critical interpretation of environmentalization process.

Keywords: Biopower; governamentality; environmentality.

\section{Biopoder e governamentalidade em Foucault}

Entre 1970 e 1984, Foucault desenvolveu uma série de abordagens em torno da problemática do poder a fim de contribuir para uma interpretação da modernidade. Convém ressaltar, no entanto, que o mesmo não se propôs a elaborar uma teoria geral e globalizante sobre o poder, capaz de ser aplicada aos mais diversos contextos e relações aí postas. Para Foucault o poder deve ser compreendido em seu funcionamento localizado, em campos, discursos e tempos específicos; daí que, ao invés de uma teoria, propõe-se a desenvolver uma analítica do poder.

No âmbito de tal analítica, uma primeira consequência é a compreensão de que a hipótese represssiva - que percebe o poder apenas como interdição, coerção, proibição, censura, negatividade - constitui apenas uma peça tática no engendramento das tecnologias de poder e da vontade de saber. O poder não deve, então, ser compreendido exclusivamente como estando relacionado ao dizer não, à imposição de limites e de castigos.

O poder, também, não significa o exercício da dominação de um elemento ou grupo sobre outro, ou ainda, não é uma propriedade. O poder é relação entre forças. Todos se encontram enredados na teia de poder pois, nada nem ninguém, pode lhe escapar, pode lhe ser exterior ou pode dele se isentar. Nesse sentido, o poder não deve ser buscado num ponto central, num foco único.

Não há o lugar, em relação ao poder, de uma Grande Resistência. Presentes em toda a rede de poder encontram-se, portanto, múltiplos e polimorfos focos de resistências. Focos movediços e transitórios que produzem rupturas e reagrupamentos, recortes e reordenamentos estratégicos, nos cálculos dos 
indivíduos e estratos sociais.

Em oposição à hipótese repressiva, conforme leitura de Rabinow e Dreyfus (1995), a analítica do poder, engendra uma síntese alternativa denominada biopoder, que corresponde a um novo tipo de racionalidade política, cuja emergência se dá no século XVII trazendo para o âmbito das preocupações do Estado o cuidado com a vida e as coisas relativas à população. O poder que surge neste momento se desenvolverá em dois pólos: por um lado, se concentrará no corpo, buscando discipliná-lo através de sua inserção em sistemas de controle e assim torná-lo útil e dócil; por outro lado, a partir do século XVIII, irá se centrar também na espécie humana, na população, que passa então a ser considerada como constituinte da ordem geral dos seres vivos e objeto necessário de intervenções de toda uma máquina de poder que é denominada de polícia.

O polo do biopoder que atua através de procedimentos disciplinares sobre os corpos é classificado como anátomo-política do corpo bumano. Por meio de sua análise compreende-se que o corpo faz parte dos cálculos do campo político, uma vez que as relações de poder têm alcance imediato sobre ele; elas o investem, o marcam, o dirigem, o supliciam, sujeitam-no a trabalhos, obrigam-nos a cerimônias, exigemthe sinais (FOUCAULT, 1993, p. 28).

O corpo inicialmente, no âmbito das sociedades de soberania, compõe junto com as coisas, o tempo, a vida, aquilo que era passível de ser apreendido pelo poder que, condicionava-se por seu turno a defender o soberano e sua existência. Ao poder soberano, portanto, cabia o direito de decidir quem vive e quem morre. Nesta época, o corpo do criminoso produzia a verdade de sua transgressão percorrendo um trajeto que ia da tortura à execução, e no decorrer do qual era submetido a "mil mortes". O corpo era assim exposto a um espetáculo de suplícios, esquartejamentos, amputações, intrínsecos aos atos de punições

Ao fim do século XVIII e início do XIX, verifica-se uma transformação da punição com a mitigação e desaparecimento dos corpos supliciados. A justiça deverá, ao invés de se vingar, punir, que é compreendido como uma arte dos efeitos. Doravante não será mais o corpo a ser atingido mas a alma. Instaurase a prática de um poder que visa disciplinar os indivíduos por meio de uma tecnologia de poder chamada de máquina panóptica, panoptismo, panóptico.

A máquina de controle que é instaurada no âmbito das sociedades 
disciplinares possui uma morfologia que possibilita uma vigilância sobre os indivíduos e um reconhecimento dos mesmos de modo a não deixar que se furtem ao olhar disciplinador do poder. Não há aí como refugiar-se em espaços confusos e sombreados posto que estes foram milimetricamente calculados a fim de permitir que o vigiar seja um exercício constante e otimizado.

A dimensão do biopoder que se acerca dos corpos através da máquina panóptica, articula-se ainda com uma dimensão em que estes corpos mesmos se inscrevem na condição de espécies pertencentes a um determinado conjunto populacional, possuidor de leis e regularidades próprias e que se referem à taxas de natalidade, morbidade, duração da vida, etc. Esta dimensão do biopoder em que a vida entra nos cálculos de atuação Foucault a chamará de biopolítica. Ela representa a emergência da esfera biológica no palco das lutas políticas.

Buscando os elementos que dão suporte para o surgimento do biológico como saber sobre a vida e a possibilidade de controle da mesma, Foucault identifica o aparecimento de um fenômeno capital (como problema teórico e como problema político) do mundo moderno: a população. Em relação ao surgimento da população Foucault assinala o seguinte:

O grande crescimento demográfico do Ocidente europeu durante o século XVIII, a necessidade de coordená-lo e de integrá-lo ao desenvolvimento do aparelho de produção, a urgência de controlá-lo por mecanismos de poder mais adequados e mais rigorosos fazem aparecer a "população" - com suas variáveis de números de repartição espacial ou cronológica, de longevidade e de saúde - não somente como problema teórico mas como objeto de vigilância, análise, intervenção, operações transformadoras, etc. Esboça-se o projeto de uma tecnologia da população: estimativas demográficas, cálculos da pirâmide das idades, das diferentes esperanças de vida, das taxas de morbidade, estudo do papel que desempenham um em relação ao outro o crescimento das riquezas e da população, diversas incitações ao casamento e à natalidade, desenvolvimento da educação e da formação profissional (...). Os traços biológicos da população se tornam elementos pertinentes para uma gestão econômica e é necessário organizar em volta deles um dispositivo que assegure não apenas 
sua sujeição mas o aumento constante de sua utilidade (FOUCAULT, 1992, p. 198).

A colocação da população como problema remete à uma análise do poder tendo em vista a questão do governo. Aqueles que governam percebem que já não têm que se ver às voltas com sujeitos ou um povo, mas com o que diz respeito à população. E governo para Foucault, conforme verificamos em Maia (1995), não tem necessariamente de haver com a máquina burocrática ou o grupo que gere a coisa pública, que administra a máquina estatal. O governo diz respeito às formas que orientam a condução de indivíduos ou grupos. A estruturação do campo de ação dos outros é o que se compreende por governar (Cf. MAIA, p. 100). Estamos diante de uma arte de governar. Aqui não se governam territórios, mas coisas. $\mathrm{E}$ isso significa que o governo ocupa-se de homens em suas relações com riquezas, recursos, territórios, clima etc., em relação com seus costumes, hábitos e em relação com a fome, a epidemia, a morte.

As práticas de governo antes de serem exteriores são imanentes ao Estado. E permitem um controle e vigilância tão atenta quanto a do pai de família (FOUCAULT, 1992, p. 281). Isso possibilita a gerência da população no nível de fenômeno que visa resultados globais e, fundamentalmente, sua gestão num nível mais minucioso, profundo e detalhado.

Toda esta análise desenvolvida por Foucault é para dizer que o importante na compreensão de nossa contemporaneidade não é o modo através do qual as sociedades se estatizaram, mas como o Estado entrou naquilo que denominou de era da governamentalidade. É através da governamentalização do Estado, das táticas de governo que permitem distinguir o que concerne ou não à esfera estatal, ao público e ao privado, que este mesmo Estado pôde sobreviver.

Governamentalidade, para Foucault, é um conceito que se refere a três coisas:

1- o conjunto constituído pelas instituições procedimentos, análises e reflexões, cálculos e táticas que permitem exercer esta forma bastante específica e complexa de poder, que tem por alvo a população, por forma principal de saber a economia política e por instrumentos técnicos essenciais os dispositivos de segurança. 
2- a tendência que em todo o Ocidente conduziu incessantemente, durante muito tempo, à preeminência deste tipo de poder, que se pode chamar de governo, sobre todos os outros - soberania, disciplina etc. - e levou ao desenvolvimento de uma série de aparelhos específicos de governo e de um conjunto de saberes.

3- o resultado do processo através do qual o Estado de justiça da Idade Média, que se tornou nos séculos XV e XVI Estado administrativo, foi pouco a pouco governamentalizado (FOUCAULT, 1992, p. 291-292).

Dentre esses processos próprios da vida, com os quais a governamentalidade terá de lidar cabe aqui apontar a preocupação as relações entre a espécie humana e o meio. De acordo com Foucault, no momento em que a biopolítica se coloca a questão destas relações é que o meio geográfico, climático e hidrográfico torna-se objeto de estudo detalhado. E os problemas que são abordados são próprios do mundo urbano: trata-se de problemas de um meio que não é natural, um meio criado pelo homem-espécie; problemas essencialmente da cidade.

Ao final do século XVIII, funda-se a bigiene social, que irá definir, tendo em vista a saúde e a limpeza, o modo de fixação espacial da população. Surge, portanto, a necessidade de uma organização dos espaços complementada com o fato de que o saber médico passa a ser decisivo para tal, posto que está mais sensibilizado para uma análise do ambiente, do lugar e da temperatura.

Nesta época os médicos eram, de certa forma, especialistas do espaço. Eles formulavam quatro problemas fundamentais: o das localizações (climas regionais, natureza dos solos, umidade e secura: sob o nome de "constituição", eles estudavam esta combinação dos determinantes locais e das variações sazonais que favorece em dado momento determinado tipo de doença); o das coexistências (seja dos homens entre si: questão da densidade e da proximidade; seja dos homens e das coisas: questão das águas, dos esgotos, da ventilação; seja dos homens e dos animais: questão dos matadouros, dos estábulos; seja dos homens e dos mortos: questão dos cemitérios); o das moradias (habitat, urbanismo); o dos deslocamentos (migração dos homens, propagação das doenças) (FOUCAULT, 1992, p. 214). 
Observamos, pois, que, ao tratar das relações entre a população e o meio, Foucault não se coloca como empiricidades a serem investigadas o problema da degradação ambiental, da escassez dos recursos, da extinção de espécies e nem cogita, então, de uma análise das estratégias formuladas para o controle destes. Todavia, entendemos que o biopoder identificado por este autor, contemporaneamente se coloca tais problemas. Se, o final do século XVIII representa uma época de preocupação com a higiene social, com a fixação espacial de enormes contingentes populacionais e a saúde do meio citadino, a segunda metade do século XX até os dias atuais, tem se constituído numa época de preocupação com o que se convencionou chamar de crise ambiental.

E, na crise ambiental do mundo contemporâneo, subjaz a preocupação fundamental do biopoder: a vida, o equilíbrio global, a segurança do conjunto em relação aos seus perigos internos (FOUCAULT, 1999: 296). Tendo em vista os riscos em escala planetária com os quais convivemos, encontramo-nos em uma época de excessos do biopoder.

Esse excesso de biopoder aparece quando a possibilidade é técnica e politicamente dada ao homem, não só de organizar a vida, mas de fazer a vida proliferar, de fabricar algo vivo, de fabricar algo monstruoso, de fabricar - no limite - vírus incontroláveis e universalmente destruidores (Ibid. p. 303).

\section{A Ambientalização da Natureza}

Com a emergência da questão ecológica-ambiental como uma das esferas fundamentais da sociedade global, podemos perceber que as análises apresentadas por Foucault a respeito de um poder e saber que tem por objeto a vida, está a falar de nossa época, de como uma profusão de saberes acerca da vida instaura um regime de disciplina e controle cuja intensidade não fora experimentada antes. E se assim o é, isso se deve ao fato de que a vida concerne agora ao planeta Terra, que já não diz respeito apenas à um conceito de Geografia Física, mas a um novo objeto histórico. Pensamos que é esta colocação daquilo que concerne a vida num foco em escala planetária que significa afirmarmos que vivemos uma época de excessos do biopoder.

No contexto de agudização do biopoder um fenômeno de escala global 
constitui um dos caracteres fundamentais da contemporaneidade, a saber, a ambientalização. Por ambientalização entendemos o processo levado a cabo por uma proliferação discursiva - técnico-científica articulada em todos os âmbitos da vida econômica, política e cultural moderna - que transforma a natureza em ambiente.

A interpretação do processo de ambientalização da Terra a partir das discussões postas por Foucault, em sua caracterização dos regimes de poder e saber instaurados nas modernas sociedades, permitiram ao cientista político norte-americano Timothy W. Luke, perceber as inter-relações existentes entre o conhecimento e as práticas de controle, e compreender, ainda, que o meio ambiente é antes de tudo um artefato histórico produzido por intervenções tecnocientíficas sobre a natureza e que, no âmbito dos estudos científicos, gera novas empiricidades. Tomando como unidade de fundamentação empírica os discursos construídos em torno da crise ecológica vista sob a ótica do governo, grupos de pesquisadores e movimento ambientalista dos Estados Unidos, Luke assinala o seguinte:

The environment, if one follows Foucault's lines of reasoning, must not be understood either as the naturally given sphere of all ecological processes that human power keeps under control or as a mysterious domain of obscure terrestrial events which human knowledge works to explain. Instead, it emerges as a historical artifact that is largely constructed by tecnocientific interventions, because it cannot remain an occluded reality that difficult to comprehend. In this great network of technical interventions into Nature, the simulation of spaces, the intensification of resources, the incitement of discoveries, the formation of special knowledges, the strengthing of controls, and the provocation of resistances all can be linked to another as 'the empiricities' of academic environmental studies (LUKE, 1997, p. 5)

Luke percebe que há um contínuo esforço para reinventar a natureza, o que no caso das modernas sociedades, corresponde à ampliação dos modos de efetivar-se o bio-poder no momento mesmo em que a população humana cresce. Isso possibilita uma articulação entre a exploração econômica dos recursos naturais com o manejo racional desses. 
"Ambiente", "ambientalismo" e "ambientalistas" são palavras usadas hoje de forma tão corriqueira que nos esquecemos que as mesmas compõem o conjunto discursivo por meio do qual se articulam os sistemas de biopoder contemporâneos. São ecodicções por meios das quais passamos nos referir à natureza como "ambiente".

Cabe aqui assinalar brevemente o significado da palavra ambiente e suas implicações na constituição de uma máquina de controle. Em português, assim como em francês, esta palavra está relacionada à ideia de espaço, sítio; cercar ou envolver (FERREIRA, 1986, p. 101).

Em inglês, as relações semânticas de ambiente com environmentsão parecidas, porém, de acordo com Luke, uma análise desta última traz desdobramentos significativos: environment seria uma condição de existência dada pelo verbo environ (cercar, envolver, sitiar) e o gerúndio environing assinalaria uma ação estratégica que fisicamente sitia, cerca, alguém ou alguma coisa. $\mathrm{O}$ autor afirma ainda que, environing denotaria vigilância ou observação de um lugar ou de pessoas. Disto resulta que an environment act, even though the connotations of most contemporary greenspeak suggest othewise, is a disciplinary move (LUKE, 1997: 8).

$\mathrm{O}$ ambiente (environment) constituiu-se, deste modo, como o meio através do qual o biopoder passa a regular a vida, faz proliferar discursos que colocam em foco o perigo da degradação ambiental, dos riscos de extinção de espécies, do uso racional dos recursos e da superpopulação. O regime de biopoder só agudiza-se quando a questão ecológica passa a integrar o conjunto disciplinar posto no âmbito do crescimento e do desenvolvimento intensivo das sociedades contemporâneas.

Luke procura articular o conceito de governamentalidade desenvolvido por Foucault com um conceito derivado diretamente deste primeiro: a ambientalidade. Assim como, no caso da governamentalidade, pode-se perceber uma mobilização de concepções, códigos e procedimentos que vão gerar "verdades" ou "saberes" na intenção de dispor adequadamente as coisas, podem-se perceber também esses esforços de mobilização agora fundados em regimes de ambientalidade.

Vivenciamos um processo de ambientalização da natureza. Neste, o mundo passa a ser visto por um olhar que o ambientaliza a partir dos diversos centros produtores de saber, que no caso específico, produzem ecoconhecimentos (eco-knowledges) com vistas ao manejo racional dos 
recursos naturais; produzem códigos disciplinares que buscam viabilizar um planejamento que permite a constituição de uma máquina de vigilância que estará atenta à saúde da população global e à sobrevivência do planeta. Isto resulta que

The individual human subject of today, and all of his or her unsustainable practices, would be reshaped through this environmentality, redirected by practices, discourses, and ensembles of administration that more efficientily synchronize the bio-power of populations with the geopower of environments. Traditional codes defining human identity and difference would be reframed by systems of environmentality in new equations for making comprehensive global sustainability calculations as the bio-power of populations merges with the ecopower of environments. (Ibid. p. 75).

A Terra, objeto histórico, para Luke, pode então ser taquigrafada com duas metáforas derivadas das abordagens foucaultianas: Astropanóptico ou Panóptico Verde. Os efeitos deste astropanóptico podem ser percebidos em diversos discursos geo-econômicos que reafirmam a necessidade de uma vigilância ambiental e redimensionam, assim, o discurso das corporações e agências estatais, que passam a inclinar-se para a uma consideração dos regimes da natureza.

Para Luke, esse processo de ambientalização da Terra assinala para o nosso tempo uma verdadeira Revolução Copernicana, marcada por demandas antropogênicas que requerem uma visão biocêntrica na qual a natureza objetivamente ressurja relacionada a formas de gestão que a considerem enquanto ecossistema, base de recursos, ambiente. Dessa racionalidade ambiental, que passa a envolver profundamente todos os âmbitos da vida contemporânea, resulta, então, uma época na qual os

environmentalists see from above and from without, like the NASA-eyed view of Earth from Apollo spacecraft, through the enveloping astropanoptic designs of administratively controllable terraformed systems. ${ }^{35}$ Encircled by enclosures of alarm, environments can be disassembled, recombined, and subjected to expert managers' disciplinary designs. Beset 
and beleaguered by these all-encompassing interventions, environments as ecosystems and terraformations can be redirected to fulfill the ends of new economic scripts, managerial directives or administrative writs (LUKE, 1997, p. 8).

Desenvolvimento sustentável, ecodesenvolvimento, eco-economia, entre outros termos, compõem o conjunto dos discursos que dizem respeito ao exercício administrativo do Panóptico Verde. Este exercício irá se materializar por meio das avaliações sobre o uso inadequado dos recursos naturais e a possibilidade de esgotamento dos mesmos, aliadas a uma agudização intensa da deterioração da qualidade de vida, gerando a necessidade de se repensar a relação homem/natureza.

No século XX, nas décadas de 50 e 60, sob as ameaças de uma hecatombe nuclear, poluição da atmosfera etc., os governos, cientistas, organizações ambientalistas e grupos sociais diversos passaram a discutir um conjunto de signos que assinalavam uma crise ambiental de proporções planetárias.

É nesta conjuntura que é realizada em 1972 uma Conferência Mundial sobre o Meio Ambiente Humano, a Conferência de Estocolmo, que envolveu aproximadamente 1.200, políticos, especialistas e autoridades de governo, representando 113 nações, 250 organizações não governamentais e diversas unidades da própria ONU' (GUIMARÃES, 1988, p. 261).

Esta Conferência tinha por objetivo propor estratégias para a contenção da poluição em suas diversas manifestações. Abordou também a questão do crescimento demográfico e a pressão que exerce sobre os recursos naturais.

Em relação ao crescimento demográfico, a Declaração de Estocolmo observou que El crecimiento natural de la población plantea continuamente problemas relativos a la preservación del medio, y se deben adoptar normas y medidas apropriadas, según proceda, para hacer frente a esos problemas (PNUMA, 1981, p. 49).

Um estudo do Clube de Roma, liderado por Dennis L. Meadows denominado "Limites do crescimento", e que serviu de subsídio para a Conferência de Estocolmo apontou que a estabilidade econômica e ecológica não poderia prescindir de um congelamento do crescimento populacional e do capital industrial.

Se as atuais tendências de crescimento da população mundial - industrialização, poluição, produção de 
alimentos e diminuição de recursos naturais - continuarem imutáveis, os limites de crescimento neste planeta serão alcançados algum dia dentro dos próximos cem anos. O resultado mais provável será um declínio súbito e incontrolável, tanto da população quanto da capacidade industrial (MEADOWS, apud BRUSEK, 1996, p. 103104).

Em 1974 é realizada uma conferência da UNCTAD (UN - Conference on Trade and Development) e da UNEP (UN - Environment Program) cujo produto final é a Declaração de Cocoyok, que apresenta como contribuição para o debate em torno do desenvolvimento e meio ambiente, a compreensão de que a degradação ambiental na África, América Latina e Ásia está relacionada à pobreza que leva as populações carentes a uma exploração intensa dos recursos naturais. Nos marcos desta declaração reconhece-se ainda que os países industrializados, em função de seu elevado nível de consumo, contribuem para os problemas de subdesenvolvimento. Aponta, assim, para a necessidade de que tais países baixem seu consumo e sua participação na poluição da biosfera. Estão dadas desta forma as bases para a emergência da noção de ecodesenvolvimento, cujas estratégias serão incorporadas ao relatório final de um projeto da fundação sueca Dag-HammarsKjöld, que propunha mudanças no padrão de consumo e no estilo de vida, nas formas tecnológicas hegemônicas, nas estratégias de planejamento espacial e na qualidade do meio físico. Segundo Maimom, ecodesenvolvimento significa:

Transformar o desenvolvimento numa soma positiva com a natureza, propondo que este tenha por base o tripé: justiça social, eficiência econômica e prudência ecológica. A qualidade social é medida pela melhoria do bem-estar das populações despossuídas, e a qualidade ecológica pela solidariedade com as gerações futuras (MAIMOM, 1993, p. 57).

No ano de 1987 é publicado o Relatório Brundlandt, denominado de "Nosso Futuro Comum”, que resultou do trabalho de uma comissão da ONU (A Comissão Mundial sobre Meio Ambiente e Desenvolvimento). Nesse relatório é difundido o conceito de "desenvolvimento sustentável" cujos 
eixos principais são o crescimento econômico, eqüidade social e equilíbrio ecológico. Atravessa estes eixos a ideia de que há uma responsabilidade comum com os processos em curso e de que o desenvolvimento e a exploração dos recursos naturais podem adquirir um sentido harmonioso. $\mathrm{O}$ desenvolvimento sustentável é considerado como o remédio para atacar a pobreza, causa fundamental da degradação ambiental.

Em 1992, realizou-se no Rio de Janeiro, a Conferência das Nações Unidas para o Meio Ambiente e o Desenvolvimento (CNUMAD). O objetivo desta conferência foi o estabelecimento de acordos internacionais que regulassem as ações antrópicas no meio. As 178 nações participantes trataram de questões relativas às mudanças climáticas globais e ao acesso e manutenção da biodiversidade. Foram ainda produzidas, nos marcos da CNUMAD, duas declarações: uma, que ficou conhecida como Carta do Rio, e que estabelecia alguns princípios para a preservação da vida na Terra; a outra, a Declaração de Florestas, que estabelece a intenção de preservar as florestas. Produziu-se também a Agenda XXI, um plano de ação para o século XXI com o objetivo de minimizar os impactos ambientais em escala global.

Logo em seu capítulo inicial, a Agenda XXI discorre sobre os desafios que estão postos para a humanidade, a necessidade de integrá-los em termos de preocupações com o ambiente e com o desenvolvimento:

A humanidade encontra-se em um momento de definição histórica. Defrontamo-nos com a perpetuação das disparidades existentes entre as nações e no interior delas, o agravamento da pobreza, da fome, das doenças e do analfabetismo, e com a deterioração contínua dos ecossistemas de que depende nosso bem-estar. Não obstante, caso se integrem as preocupações relativas ao meio ambiente e desenvolvimento e a elas se dedique mais atenção, será possível satisfazer às necessidades básicas, elevar o nível da vida de todos, obter ecossistemas melhor protegidos e gerenciados e construir um futuro mais próspero e seguro. São metas que nação alguma pode atingir sozinha; juntos, porém, podemos - em uma associação mundial em prol do desenvolvimento sustentável (CNUMAD, 1996, p. 9). 
De Estocolmo à CNUMAD observamos, portanto, uma proliferação discursiva que tem por objeto os destinos da humanidade tendo em vista a saúde do ambiente, o que remete para uma época de excessos do biopoder, assinalada anteriormente. Percebe-se em todas estas conferências de escopo planetário, o papel fundamental da idéia de desenvolvimento sustentável enquanto argamassa ideológica, palavra de ordem, do ambientalismo e da nova tecnocracia verde.

Alier, em sua crítica da aplicação de conceitos próprios da Ecologia às esferas da Cultura e da Economia, engendrada no processo de ambientalização, aponta que a idéia de desenvolvimento sustentável remete a um conceito da ciência ecológica a saber, a capacidade de sustentação, que refere-se à população máxima de uma espécie que pode manter-se indefinidamente em um território, sem provocar uma degradação na base dos recursos que leve a diminuir esta população no futuro" (ALIER, 1998, p. 91).

Desse modo, de acordo com Alier, as argumentações baseadas na capacidade de sustento, na sustentabilidade e no desenvolvimento sustentável são ideológicas em sua aplicação e constituem-se em esforços de biologizar o que pertence às esferas da cultura, da política e da economia. Esta é outra forma de explicitar os excessos do bio-poder contemporâneo, de se referir ao fenômeno da ambientalidade identificado por Luke.

Nesse contexto, a vigilância, o disciplinamento e a difusão do ideário ambientalista, ocorrem através de diversas e polimorfas formas institucionais, que funcionam como os olhos do biopoder.

Para Luke, os diversos discursos forjados por estes agentes políticos ao buscarem consolidar conceitos e práticas referentes à sustentabilidade (sustainability), apresentam-se por um lado, como articulações para a preservação da diversidade biótica do Planeta, e por outro lado, representam um esforço de reordenamento para a garantia de desenvolvimento do capitalismo. Aponta o autor citado também para um novo modo de subjetividade, agora ambientalizada, que as declarações sobre a sustentabilidade buscam produzir. Desse modo, o termo "populações tradicionais", por exemplo, pode ser interpretado como um das formas de subjetividade ambientalizada produzida na proliferação discursiva da sustentabilidade. Observando o discurso 
ambientalista contemporâneo, podemos perceber o quanto temos de excessos de biopoder em nossa época. A natureza foi transformada em ambiente, os territórios reconfigurados em função do equilíbrio ecológico da Terra e grupos sociais diversos foram transformados em sociedades ecologizadas, biologizadas, ambientalizadas.

O que está em questão, então não é saber se em meio aos debates sobre os caminhos a serem percorridos rumo a uma sociedade baseada nos princípios da sustentabilidade há um lado certo, se um deles é portador de princípios mais legítimos e verdadeiros, se é possível ao final de uma comparação, optar por um deles.

Para a reflexão sociológica, o que se coloca é a necessidade de retirar essa proliferação discursiva produzida no contexto desse regime de ambientalidade da sua quietude, dessa condição naturalizada com que se dissemina, e questionála naquilo que tem produzido em termos de efeito de poder.

Recorrendo às reflexões de Wittgenstein, diríamos que, contentarse com os elementos primeiros que as palavras forjadas no processo de ambientalização nos indicam (risco de degradação ambiental, sustentabilidade, conservação, "populações tradicionais" etc.), é condenar-se a não ultrapassar o momento do "ensino ostensivo das palavras". Wittgenstein (1994) assinala que este momento não é explicativo, e sim, treino, estabelecimento de uma ligação associativa entre a palavra e a coisa. A definição ostensiva só explica alguma coisa quando está claro o papel que a palavra tem a desempenhar na linguagem e, para tal, tem-se de saber (ou poder) alguma coisa antes de poder questionar a denominação (WITTGGENSTEIN, 1994, p. 31).

E para ir além do ensino ostensivo das palavras, é preciso compreender os "subúrbios da linguagem", penetrar por entre uma rede de ruelas e praças, casas velhas e novas, e casas com remendos de épocas diferentes; e isto tudo circundado por uma grande quantidade de novos bairros, com ruas retas e regulares e com casas uniformes (Ibid. p. 23).

Tomando como referência as abordagens de Foucault sobre a constituição de um biopoder e a governamentalização do Estado nas modernas sociedades, e complementando-as com os insights daí obtidos por Luke, o que o olhar sociológico buscou neste trabalho foi percorrer os "subúrbios da linguagem" do regime de ambientalidade, compreender a emergência de tais discursos suas reconfigurações em nossa época e as diferentes práticas que o engendram 
- como produtos de um processo vertiginoso de ambientalização da natureza.

No escopo do presente trabalho, vimos que a proliferação discursiva e as estratégias referentes ao meio ambiente significam um maior exercício de saber e de poder sobre a vida. A ambientalização, ao invés de apontar para a possibilidade de emancipação dos homens, significa um refinamento maior, uma otimização dos recursos de controle no âmbito das sociedades disciplinares. Se antes os indivíduos eram aprisionados em espaços fechados (hospícios, hospitais, orfanatos, prisões) eles agora se encontram na condição de prisioneiros, enclausurados, da própria Terra, das práticas e discursos referentes aos espaços disciplinares forjados no escopo da ambientalidade.

\section{Referências}

ALIER, Joan Martínez. Da economia ecológica ao ecologismo popular. Blumenau: Ed. da Furb, 1998.

BRÜSEK, Franz Josef. Desestruturação e Desenvolvimento. In: FERREIRA, Leila da Costa e VIOLA, Eduardo (Orgs.). Incertezas de sustentabilidade na globalização. Campinas: Editora da Unicamp, 1996.

CNUMAD. Agenda 21. Rio de Janeiro: Senado Federal, 1996.

COMISSÃO MUNDIAL SOBRE MEIO AMBIENTE E DESENVOLVIMENTO. Nosso Futuro Comum. Rio de Janeiro: Fundação Getúlio Vargas, 1991.

FERREIRA, Aurélio Buarque de Holanda. Novo Dicionário Aurélio da Lingua Portuguesa. Rio de Janeiro: Nova Fronteira, 1986.

FOUCAULT, Michel (1992). Microfísica do Poder. Rio de Janeiro, 10. ed., Graal. . História da Sexualidade I: A vontade de saber. Rio de Janeiro, Graal, 1993.

LUKE, Timothy W. On Envirnmentality: Geo-Power and Eco-Knowledge in the Discourses of Contemporary Environmentalism. In: Cultural Critique. Indiana, 1995, p. 57-81. 
. The (Un) Wise (Ab) Use of Nature: Environmentalism as Globalized Consumerism? Disponível em: http://www.cddc.vt.edu/tim/tims/Tim528. htm. Acesso em 4 de abril de 2000.

- Generating Green Governmentality: A Cultural critique of Environmentalis Studies as a Power/Knowledge Formation. Disponível em: http://www.cddc.vt.edu/tim/tims/Tim514ahtm. Acesso em 4 de abril de 2000.

MAGALHÃES, Sônia Barbosa. A investigação sociológica e a dimensão ambiental. In: LIMA, Jacob Carlos et all. (Orgs.). Trabalho, Sociedade e Meio Ambiente. João Pessoa: Ed. Universitária/UFPB, 1997.

MAIA, Antônio C. Sobre a analítica do poder de Foucault. In: Tempo Social. São Paulo: USP, 7(1-2), 1995, p. 83-103, outubro.

MAIMON, Dália. A Economia e a Problemática Ambiental. In: VIEIRA, Paulo Freira e MAIMON, Dália (Orgs.). As Ciências Sociais e a Questão Ambiental: rumo à interdisciplinaridade. Belém/São Paulo: APED e UFPA, 1993.

PNUMA. La Declaración de Estocolmo. In: En Defensa de la Tierra: los documentos básicos sobre el medio ambiente, 1981, p. 49-125.

RABINOW, Paul e DREYFUS, Hubert. Michel Foncault: uma trajetória filosófica (para além do estruturalismo e da hermenêutica). São Paulo: Forense Universitária, 1995.

WITTGENSTEIN, Ludwig. Investigações Filosóficas. Petrópolis: Vozes, 1994. 